\title{
The Endocannabinoid System and its Modulation by Phytocannabinoids
}

\author{
Vincenzo Di Marzo ${ }^{1} \cdot$ Fabiana Piscitelli ${ }^{1}$
}

Published online: 14 August 2015

(C) The American Society for Experimental NeuroTherapeutics, Inc. 2015

\begin{abstract}
The endocannabinoid system is currently defined as the ensemble of the two 7-transmembrane-domain and G protein-coupled receptors for $\Delta^{9}$-tetrahydrocannabinol (but not for most other plant cannabinoids or phytocannabinoids) - cannabinoid receptor type-1 $\left(\mathrm{CB}_{1} \mathrm{R}\right)$ and cannabinoid receptor type-2 $\left(\mathrm{CB}_{2} \mathrm{R}\right)$; their two most studied endogenous ligands, the "endocannabinoids" $N$-arachidonoylethanolamine (anandamide) and 2-arachidonoylglycerol (2-AG); and the enzymes responsible for endocannabinoid metabolism. However, anandamide and 2-AG, and also the phytocannabinoids, have more molecular targets than just $\mathrm{CB}_{1} \mathrm{R}$ and $\mathrm{CB}_{2} \mathrm{R}$. Furthermore, the endocannabinoids, like most other lipid mediators, have more than just one set of biosynthetic and degrading pathways and enzymes, which they often share with "endocannabinoid-like" mediators that may or may not interact with the same proteins as $\Delta^{9}$-tetrahydrocannabinol and other phytocannabinoids. In some cases, these degrading pathways and enzymes lead to molecules that are not inactive and instead interact with other receptors. Finally, some of the metabolic enzymes may also participate in the chemical modification of molecules that have very little to do with endocannabinoid and cannabinoid targets. Here, we review the whole world of ligands, receptors, and enzymes, a true "endocannabinoidome", discovered after the cloning of
\end{abstract}

Electronic supplementary material The online version of this article (doi:10.1007/s13311-015-0374-6) contains supplementary material, which is available to authorized users.

Vincenzo Di Marzo

vdimarzo@icb.cnr.it

1 Institute of Biomolecular Chemistry, Consiglio Nazionale delle Ricerche, Via Campi Flegrei 34, Comprensorio Olivetti, 80078 Pozzuoli, NA, Italy
$\mathrm{CB}_{1} \mathrm{R}$ and $\mathrm{CB}_{2} \mathrm{R}$ and the identification of anandamide and 2-AG, and its interactions with phytocannabinoids.

Keywords Phytocannabinoids · Endocannabinoids · TRP channels $\cdot$ Endocannabinoidome

\section{Introduction}

Giving a definition of the complex endogenous signaling system known as the "endocannabinoid system" is becoming an increasingly difficult task. In fact, the number of potential components of this system, which was originally identified from studies on the mechanism of action of the psychotropic ingredient of some varieties of cannabis, $\Delta^{9}$-tetrahydrocannabinol (THC), is increasing with the passing years, and the definition of "endocannabinoid" is also bound to change in the near future [1].

At the turn of the century, the endocannabinoid system was defined as the ensemble of 1) two 7-transmembrane-domain and $\mathrm{G}$ protein-coupled receptors (GPCRs) for THC - cannabinoid receptor type-1 $\left(\mathrm{CB}_{1} \mathrm{R}\right)$ and cannabinoid receptor type$\left.2\left(\mathrm{CB}_{2} \mathrm{R}\right) ; 2\right)$ their 2 most studied endogenous ligands, the "endocannabinoids" $\mathrm{N}$-arachidonoylethanolamine (anandamide) and 2-arachidonoylglycerol (2-AG); and 3) the 5 enzymes believed, at that time, to be uniquely responsible for endocannabinoid biosynthesis [i.e., $N$-acyl-phosphatidyl-ethanolamine-selective phospholipase D (NAPE-PLD) and diacylglycerol lipases (DAGL) $\alpha$ and $\beta$, for anandamide and 2-AG, respectively] and hydrolytic inactivation [i.e., fatty acid amide hydrolase (FAAH) and monoacylglycerol lipase (MAGL), for anandamide and 2-AG, respectively] (Fig. 1) [2]. This definition, however, presented a few semantic problems [1]: 1) of the $>80$ cannabinoids naturally found in cannabis (with different relative composition depending on the cannabis variety), only THC and its less abundant propyl 


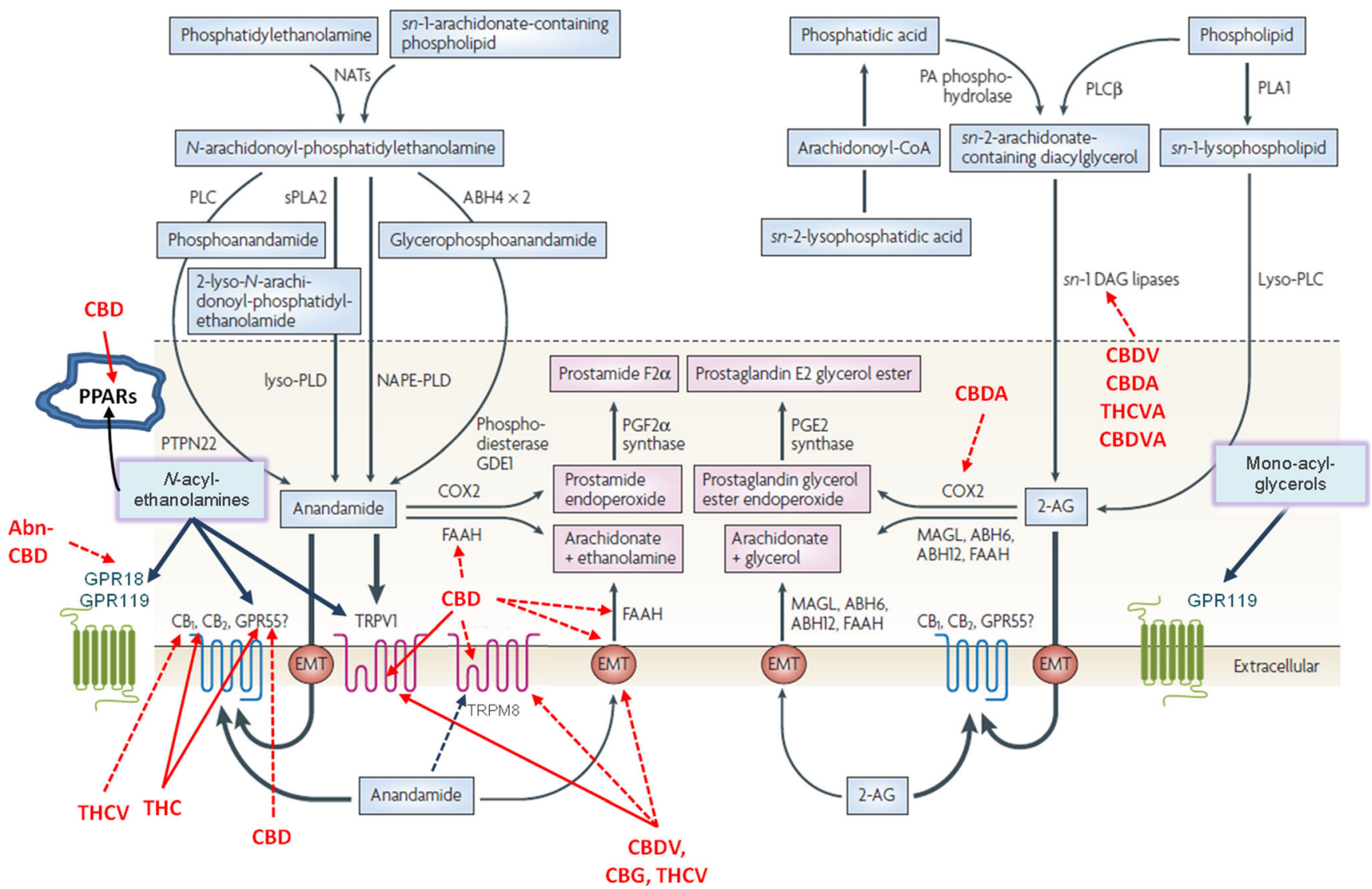

Fig. 1 Complexity, redundancy, and promiscuity of the endocannabinoid system: the "endocannabinodome" and the interactions therewith of plant cannabinoids. Several often concurrent pathways underlie both the biosynthesis and the inactivation of the 2 most studied endocannabinoids, anandamide, and 2-arachidonoylglycerol (2-AG). Anandamide biosynthetic precursors, the $N$-arachidonoyl-phosphatidylethanolamines, are produced from the remodeling of phospholipids via the action of $\mathrm{N}$ acyl-transferases (NATs). They are then converted to anandamide, either in 1 step, by $N$-acyl-phosphatidylethanolamine-selective phospholipase D (NAPE-PLD), or in sequential steps, i.e. by $\alpha, \beta$-hydrolase-4 (ABHD4) followed by phosphodiesterase GDE1; or soluble phospholipase A2 (sPLA2) followed by lysophospholipase D (lyso-PLD); or by phospholipase C (PLC) enzymes followed by phosphatases such as PTPN22. The $s n$-2-arachidonate-containing diacylglycerols serving as biosynthetic precursors for 2-AG are in most cases produced from the action of PLC $\beta$ but can also come from phosphatidic acid (PA) via PA phosphohydrolase. However, 2-AG can be also produced from sn-1-lysophospholipids via the sequential action of phospholipase A1 (PLA1) and lyso-phospholipase $\mathrm{C}$, or (not shown here) from the dephosphorylation of lysophosphatidic acid. These biosynthetic pathways are shared by anandamide and 2-AG with other $\mathrm{N}$-acyl-ethanolamines and 2-monoacyl-glycerols, respectively. These congeners, in most cases, do not activate directly the 2 cannabinoid receptors (denoted as $\mathrm{CB}_{1}$ and $\mathrm{CB}_{2}$ here, and as $\mathrm{CB}_{1} \mathrm{R}$ and $\mathrm{CB}_{2} \mathrm{R}$ in the main text), but have other targets, some of which shown here, such as orphan G-protein-coupled receptors (GPR55, GPR18, GPR119); the transient receptor potential of vanilloidtype 1 (TRPV1) channel; and peroxisome proliferator-activated nuclear receptors (PPARs). However, also anandamide and, to a lesser extent, 2-AG, have been suggested to be capable of activating some of these targets, particularly TRPV1 and GPR55. Anandamide also inhibits the transient receptor potential melastatin type-8 (TRPM8) channel (blue broken arrow). Both anandamide and 2-AG, following their cellular reuptake by cells, which might be facilitated by a yet-to-be-characterized endocannabinoid membrane transporter (EMT), are inactivated inside cells by enzymatic hydrolysis, respectively by fatty acid amide hydrolase (FAAH) and monoacylglycerol lipase (MAGL). In some cells FAAH, $\alpha, \beta$-hydrolase-6 (ABHD6) and, even less frequently, $\alpha, \beta$-hydrolase- 12 (ABHD12), can also hydrolyze 2-AG. These enzymes are also responsible for the enzymatic hydrolysys of other $N$-acyl-ethanolamines and 2-mono-acyl-glycerols, respectively, although $\mathrm{N}$-palmitoylethanolamine is preferentially hydrolyzed by $N$-acyl-ethanolamine acid amidohydrolase (not shown). The 2 endocannabinoids, but not their nonpolyunsaturated congeners, can also be oxidized by cyclooxygenase- 2 (COX-2), and then processed by prostaglandin synthases, to produce prostamides, in the case of anandamide, and prostaglandin-glycerol esters, in the case of 2-AG. This latter endocannabinoid, via the action of MAGL or ABHD6, can also act as biosynthetic precursor for the nonphospholipase A2-mediated production of prostanoids. Apart from $\Delta^{9}$ tetrahydrocannabinol (THC), plant cannabinoids mentioned in the main text, such as cannabidiol (CBD), CBD acid (CBDA), cannabidivarin (CBDV), cannabigerol (CBG), $\Delta^{9}$-tetrahydrocannabivarin (THCV), THCV acid (THCVA), and CBDV acid (CBDVA), either activate (red solid arrows) or inhibit (red broken arrows) some of the receptors and enzymes of the "endocannabinoidome". However, they often do so at medium-high micromolar concentrations, and the weight of such interactions in their pharmacology, as compared with others that they have also been suggested to exert, has not yet been fully assessed. Abn$\mathrm{CBD}=$ abnormal cannabidiol; $\mathrm{DAG}=$ diacylglycerol; $\mathrm{PLC} \beta=$ phospholipase $\beta$. Adapted from Di Marzo [58] 
analogue, $\Delta^{9}$-tetrahydrocannabivarin (THCV), are capable of binding with high affinity to $\mathrm{CB}_{1} \mathrm{R}$ and $\mathrm{CB}_{2} \mathrm{R}$ (with agonist and antagonist activity for THC and THCV, respectively); hence, these 2 receptors should not be defined as "cannabinoid" receptors, but rather as THC/THCV receptors [alternatively the definition of "cannabinoid receptor" should also include those proteins that often bind to cannabinoids, such as the thermosensitive transient receptor potential (TRP) cation channels (thermo-TRPs) [3] (see below)]; 2) as a consequence, "endocannabinoids" should not be the endogenous ligands of $\mathrm{CB}_{1} \mathrm{R}$ and $\mathrm{CB}_{2} \mathrm{R}$, but rather the ligands of all those "cannabinoid receptors" that uniquely and selectively bind to cannabinoids in general (thus, anandamide and 2-AG might not be the only endocannabinoids); and 3) again, as a consequence, "endocannabinoid enzymes" would not only be NAPE-PLD, the two DAGLs, FAAH, and MAGL, but also other enzymes responsible for the biosynthesis and inactivation of the other mediators to be eventually included in the list of the endocannabinoids.

Although that depicted above would seem like the natural "evolution" of the definition of the "endocannabinoid system", things are likely to be even more complicated. First, endocannabinoids, and also cannabinoids, have more molecular targets than just $\mathrm{CB}_{1} \mathrm{R}, \mathrm{CB}_{2} \mathrm{R}$, or thermo-TRPs, and these receptors appear to extend also to proteins that are targeted by other endogenous and exogenous substances. Furthermore, anandamide and 2-AG, like most other lipid mediators, have more than just 1 set of biosynthetic and degrading pathways and enzymes each (Fig. 1), which they often share with "endocannabinoid-like" mediators that may or may not be part of the extended definition of "endocannabinoids" provided above, that is, they may or may not interact with the same proteins to which non-THC cannabinoids bind. In some cases, these degrading pathways and enzymes lead to molecules, such as the prostamides and prostaglandin-glycerol esters (Fig. 1), which are not inactive but instead interact with other receptors, that is, these enzymes are "degrading" for endocannabinoids and "biosynthetic" for other mediators. Finally, some of these enzymes may also have additional completely different functions, for example participate in the chemical modification of molecules that have very little to do with endocannabinoid and cannabinoid targets.

As a result of the above reasoning, some authors now use an extended definition of the endocannabinoid system, such the "enlarged endocannabinoid system". We, instead, for the sake of clarity, prefer to use the definition of "endocannabinoid-like" mediators [1], that is, mediators belonging to the same chemical class as the endocannabinoids (i.e., amides or esters of long-chain fatty acids), which are not necessarily linked metabolically to anandamide and 2-AG, and have as preferential receptors proteins different from $\mathrm{CB}_{1} \mathrm{R}$ and $\mathrm{CB}_{2} \mathrm{R}$. The ensemble of endocannabinoids, endocannabinoid-like mediators, and their several receptors and metabolic enzymes could then be defined as the "endocannabinoidome" [4]. This is not because its function is necessarily overlapping with that of $C_{1} R$ and $C_{2} R$, but because the genetic or pharmacological manipulation of one member of this new "ome" may ricochet on the activity of these 2 receptors by indirectly influencing the levels or action of anandamide and 2-AG (Fig. 1); hence, the necessity of studying the impact of such manipulations on this system as a whole, by employing the typical methodologies (genomics, transcriptomics, kinomics, metabolomics, lipidomics, etc.) used to investigate the expression and activity of several genes, proteins, and metabolites at once.

\section{Endocannabinoids, Plant cannabinoids and Thermo-TRPs}

The first evidence that anandamide and capsaicin, that is, the prototypical plant-derived activator of heat-sensitive TRP channels of vanilloid type-1 (TRPV1), and pungent component of capsicum, have something in common came when some synthetic TRPV1 agonists were found to inhibit the cellular reuptake of anandamide [5]. Immediately thereafter, anandamide was shown to be the first endogenous agonist of both human and rat TRPV1 channels [6], although it was soon clear that this endocannabinoid was not the only lipid mediator capable of exerting this function [7]. Anandamide was later found also to antagonize TRP channels of melastatin type- 8 (TRPM8), which are instead activated by low temperatures and menthol [8], whereas the other cold-activated TRP, the TRP channel of ankyrin type-1 (TRPA1), activated by mustard oils, was sensitive only to high micromolar concentrations of the endocannabinoid. The stimulatory, and subsequently desensitizing, effects of anandamide at TRPV1 have been reported in hundreds of studies and represent one of the most important mechanisms, after CB1 activation, through which this lipid mediator exerts its biological functions [9]. Recently, 2-AG was also shown to activate TRPV1, although at concentrations higher than those required to anandamide to produce the same effect $[10,11]$.

Importantly, both THC and non-THC cannabinoids can interact with thermo-TRPs, often in a manner similar to anandamide. The other most abundant, and nonpsychotropic, cannabinoid, cannabidiol (CBD) and, less potently, THCV, cannabigerol (CBG), cannabigerovarin $(\mathrm{CBGV})$, and cannabidivarin (CBDV), activate and desensitize human TRPV1, whereas CBD, CBDV, THCV, and CBG, as well as THC, antagonize rat TRPM8. All these compounds, as well as cannabichromene activate and desensitize rat TRPA1 $[12,13]$. Of these effects, only TRPM8 antagonism is also exerted by cannabinoids in their acid form (which is also the form in which they are naturally produced by the plant) [13]. Of other proposed heat-sensitive TRP channels, that is TRPV2, 
TRPV3, and TRPV4, only CBD, CBG, CBGV, THC, and, less potently, THCV, activate and desensitize TRPV2 [13], whereas only CBD and THCV are capable of activating and desensitizing rat TRPV3, which is potently desensitized, but not potently activated, by CBGV [14]. Finally, only THCV is a reasonably good activator of the rat TRPV4, although CBD and CBGV potently desensitize this channel [14].

It is important to emphasize that only a few of these effects, which were observed using calcium imaging techniques in intact cells, have been so far confirmed to be due to direct interactions with the channels by using, for example, patch clamp electrophysiology. In particular, this is true to date only for CBD and CBDV activation of TRPV1, TRPV2, and TRPA1 [15, 16]. Unpublished electrophysiological evidence also exists for the antagonism of TRPM8 (Thomas Voets, personal communication). Nevertheless, the abovementioned thermo-TRPs, especially in the absence of other strong and specific exogenous/xenobiotic modulators, are now considered by all means bona fide "ionotropic cannabinoid receptors", whereas $\mathrm{CB}_{1} \mathrm{R}$ and $\mathrm{CB}_{2} \mathrm{R}$ would thus be defined as "metabotropic cannabinoid receptors" $[3,17,18]$. Importantly, several "endocannabinoid-like" mediators, such as, on the one hand, the anandamide congeners $N$-palmitoylethanolamine, $N$-oleoylethanolamine, and $N$-linoleoylethanolamine, as well as several $N$-acyl-dopamines and $N$-acyl-taurines, as direct or indirect activators [11, 19-22], and, on the other hand, some $N$-acyl-serotonins, as competitive antagonists [23, 24], have been shown to interact with TRPV1 in in vitro and in vivo studies.

\section{Other Ways Through Which non-THC Plant Cannabinoids Influence the Endocannabinoid System}

Apart from activating (in the case of THC) or antagonizing (in the case of THCV) $\mathrm{CB}_{1} \mathrm{R}$ and $\mathrm{CB}_{2} \mathrm{R}$ [25], plant cannabinoids have other ways of potentially and indirectly modifying the activity of the endocannabinoid system. Most nonacid plant cannabinoids inhibit, albeit not very potently, the cellular reuptake of anandamide, and CBD is also a moderate inhibitor of anandamide hydrolysis by FAAH $[13,26]$, an effect that has been recently reported to also occur in vivo in mice and humans [27, 28]. If one remembers that several endocannabinoid-like mediators are also inactivated by FAAH (Fig. 1), a consequence of the above findings is that plant cannabinoids can affect the tissue levels of these compounds, too.

None of the cannabinoids tested thus far exerts potent inhibition of 2-AG inactivation by MAGL, although botanical extracts from cannabis varieties producing preferentially either CBG, CBG acid or, particularly, THC acid, as opposed to the pure compounds, do inhibit this enzyme at concentrations $<50 \mu \mathrm{M}$, suggesting the presence of MAGL inhibitors among the noncannabinoid components of the extracts [13]. Conversely, pure CBDV, CBG acid, CBD acid, THC acid, and CBDV acid weakly inhibit (with $\mathrm{IC}_{50}$ values in the 16.6-27.3 $\mu \mathrm{M}$ range) $2-\mathrm{AG}$ biosynthesis by DAGL $\alpha$ [13]. There are also indirect ways through which CBD (which has extremely low affinity for $\mathrm{CB}_{1} \mathrm{R}$ and $\mathrm{CB}_{2} \mathrm{R}$ ) inhibits $\mathrm{CB} 1$ activity, particularly in the central nervous system, and these have been recently reviewed by McPartland et al. [29].

Finally, at high concentrations, THCV behaves as a CB2 agonist, as shown by in vitro and in vivo studies [25, 30, 31].

\section{How do Endocannabinoid-like Mediators Influence the Activity of $C B_{1} R$ and $C B_{2} R$ ?}

Most endocannabinoid-like mediators, that is, those compounds that, according to the definition given above, are not part of the endocannabinoid system but contribute to constitute the endocannabinoidome, do not directly influence the activity of $\mathrm{CB}_{1} \mathrm{R}$ and $\mathrm{CB}_{2} \mathrm{R}$. Whilst some controversial data exist as to the capability of nonarachidonate-containing, polyunsaturated $N$-acyl-ethanolamines [32, 33], as well as of the primary amide of oleic acid and sleep-inducing factor, oleamide [34], to activate these receptors functionally, some endogenously occurring amides and esters of long chain fatty acids can influence CB1 and CB2 action only indirectly. $N$ palmitoyl-ethanolamide and, particularly, $N$-oleoyl- and $N$ linoleoyl-ethanolamide, by acting as alternative substrates for FAAH [35], can retard the degradation of anandamide, and the same is true for some unsaturated $N$-acyl-amino acids, particularly $N$-arachidonoyl-glycine $[36,37]$, and $N$-acyl-taurines [38]. Furthermore, $N$-palmitoyl-ethanolamide can reduce the expression of FAAH after prolonged exposure of human breast cancer cells [39]. Likewise, the mono-acyl-glycerols of palmitic, oleic, and linoleic acids enhance the functional activity of 2-AG at $\mathrm{CB}_{1} \mathrm{R}$ and $\mathrm{CB}_{2} \mathrm{R}$, seemingly by inhibiting 2AG enzymatic hydrolysis [40].

\section{Conclusions: The Overlap \\ Between the "Endocannabinoidome" and the "Phytocannabinoidome"}

From the evidence reviewed in this article, it is clear that the "endocannabinoidome" and the ensemble of the plant cannabinoids and their molecular targets, which could be defined by analogy as the "phytocannabinoidome", overlap to some extent. The commonalities between these 2 "omes" are even more striking if one looks at alternative targets (i.e., other than $\mathrm{CB}$ receptors and thermo-TRP channels) that have been proposed to date for endocannabinoid-like mediators and phytocannabinoids (see [41] for review). When such targets 
are receptors, they belong to all 3 major receptor classes, i.e. GPCRs, ligand-sensitive ion channels, and nuclear receptors. In particular: 1) the orphan GPCR, GPR55, has been suggested to act as target for both cannabinoids, that is, THC and $\mathrm{CBD}$, which seem to act as agonist and antagonist, respectively, for this receptor [42], and $N$-palmitoylethanolamine, which seems to be an agonist [42]. In fact, there is controversial evidence that anandamide and 2-AG may also activate GPR55, and the recent finding of CB1-GPR55 heteromers might explain why some authors have found that the 2 endocannabinoids directly activate this orphan GPCR and most others have not [43-46]. Another orphan GPCR, GPR18, is instead activated by $N$-arachidonoyl-glycine and by a synthetic CBD analogue known as abnormal-cannabidiol [47, 48]. 2) Ttype $\mathrm{Ca}^{2+}$ channels have been suggested to be inhibited by both unsaturated long chain fatty acid amides, including some $\mathrm{N}$-acylethanolamines, $N$-acyl-serotonins, and $N$-acyldopamines [49], and THC and CBD [50]. 3) peroxisome-proliferator activated receptor- $\alpha$ is activated by both anandamide congeners such as $N$-palmitoylethanolamine and $N$-oleoylethanolamine [51], which have in this nuclear receptor their preferred target, and some plant and synthetic cannabinoids [52]; instead, PPAR $\gamma$ is activated, at concentrations of $1-10 \mu \mathrm{M}$, by both CBD and anandamide or 2-AG [53, 54].

However, endocannabinoid-like mediators have additional targets, which they do not share with phytocannabinoids, and the same is true for the latter compounds. Therefore, the overlap between the "endocannabinoidome" and the "phytocannabinoidome" is only partial. Further interactions can be predicted on the basis of the capability of both polyunsaturated endocannabinoid-like mediators and plant cannabinoids to inhibit, or to be oxidized by, cytochrome $\mathrm{p} 450$ oxygenases [55, 56], which, in theory, allows the latter compounds, when administered systemically, to modulate the levels of the former. Finally, CBD acid, and much less so THC acid, were reported to inhibit cycloxygenase-2 [57], thus potentially inhibiting the formation not only of prostanoids, but also of prostamides and prostaglandin-glycerol esters. However, such interactions are yet to be demonstrated in vivo. Likewise, most of the interactions between these endogenous and xenobiotic compounds and the targets mentioned in this section have been shown to occur in vitro and their relevance to in vivo pharmacology is yet to be fully clarified. It is, in fact, also the realization that much work still needs to be done to dissect the pharmacological importance of the "endocannabinoidome" and the "phytocannabinoidome", and, hence, to evaluate fully their and biological/therapeutic relevance, that has convinced many scientists working on this topic to focus so far mostly on the "endocannabinoid system" as it was defined at the turn of the century.

The role of this system and the capability of the most abundant plant cannabinoids, namely THC and CBD, to modulate it in the framework of the treatment of neurological and neuropsychiatric disorders, is the theme of this special issue and of the following chapters.

\section{References}

1. Di Marzo V, De Petrocellis L. Fifty years of 'cannabinoid research' and the need for a new nomenclature. In: Di Marzo V (ed.) Cannabinoids, Wiley-Blackwell, Oxford, 2014, pp. 261-289.

2. Watkins BA, Kim J. The endocannabinoid system: directing eating behavior and macronutrient metabolism. Front Psychol 2015;5: 1506.

3. De Petrocellis L, Di Marzo V. Non-CB1, non-CB2 receptors for endocannabinoids, plant cannabinoids, and synthetic cannabimimetics: focus on G-protein-coupled receptors and transient receptor potential channels. J Neuroimmune Pharmacol 2010;5:103-121.

4. Di Marzo V, Wang J (eds). The endocannabinoidome. Academic Press, London, 2015.

5. De Petrocellis L, Bisogno T, Davis JB, Pertwee RG, Di Marzo V. Overlap between the ligand recognition properties of the anandamide transporter and the VR1 vanilloid receptor: inhibitors of anandamide uptake with negligible capsaicin-like activity. FEBS Lett 2000;483:52-56.

6. Zygmunt PM, Petersson J, Andersson DA, et al. Vanilloid receptors on sensory nerves mediate the vasodilator action of anandamide. Nature 1999;400:452-457.

7. Ahern GP. Activation of TRPV1 by the satiety factor oleoylethanolamide. J Biol Chem 2003;278:30429-30434.

8. De Petrocellis L, Starowicz K, Moriello AS, Vivese M, Orlando P, Di Marzo V. Regulation of transient receptor potential channels of melastatin type 8 (TRPM8): effect of cAMP, cannabinoid CB(1) receptors and endovanilloids. Exp Cell Res 2007;313:1911-1920.

9. Di Marzo V, De Petrocellis L. Why do cannabinoid receptors have more than one endogenous ligand? Philos Trans R Soc Lond B Biol Sci 2012;367:3216-3228.

10. Zygmunt PM, Ermund A, Movahed P, et al. Monoacylglycerols activate TRPV1 - a link between phospholipase C and TRPV1. PLoS One 2013;8:e81618.

11. Petrosino S, Schiano Moriello A, Cerrato S, et al. The antiinflammatory mediator palmitoylethanolamide enhances the levels of 2-arachidonoyl-glycerol and potentiates its actions at transient receptor potential vanilloid type-1 channels. Br J Pharmacol 2015 Jan 19 [Epub ahead of print].

12. De Petrocellis L, Vellani V, Schiano-Moriello A, et al. Plant-derived cannabinoids modulate the activity of transient receptor potential channels of ankyrin type-1 and melastatin type-8. J Pharmacol Exp Ther 2008;325:1007-1015.

13. De Petrocellis L, Ligresti A, Moriello AS, et al. Effects of cannabinoids and cannabinoid-enriched Cannabis extracts on TRP channels and endocannabinoid metabolic enzymes. Br J Pharmacol 2011;163:1479-1494.

14. De Petrocellis L, Orlando P, Moriello AS, et al. Cannabinoid actions at TRPV channels: effects on TRPV3 and TRPV4 and their potential relevance to gastrointestinal inflammation. Acta Physiol (Oxf) 2012;204:255-266.

15. Iannotti FA, Hill CL, Leo A, et al. Nonpsychotropic plant cannabinoids, cannabidivarin (CBDV) and cannabidiol (CBD), activate and desensitize transient receptor potential vanilloid 1 (TRPV1) channels in vitro: potential for the treatment of neuronal hyperexcitability. ACS Chem Neurosci 2014;5:1131-1141. 
16. Qin N, Neeper MP, Liu Y, Hutchinson TL, Lubin ML, Flores CM. TRPV2 is activated by cannabidiol and mediates CGRP release in cultured rat dorsal root ganglion neurons. J Neurosci 2008;28: 6231-6238.

17. Akopian AN, Ruparel NB, Jeske NA, Patwardhan A, Hargreaves KM. Role of ionotropic cannabinoid receptors in peripheral antinociception and antihyperalgesia. Trends Pharmacol Sci 2009;30:79-84.

18. Di Marzo V, De Petrocellis L. Endocannabinoids as regulators of transient receptor potential (TRP) channels: a further opportunity to develop new endocannabinoid-based therapeutic drugs. Curr Med Chem 2010;17:1430-1449.

19. De Petrocellis L, Davis JB, Di Marzo V. Palmitoylethanolamide enhances anandamide stimulation of human vanilloid VR1 receptors. FEBS Lett 2001;506:253-256.

20. Ambrosino P, Soldovieri MV, Russo C, Taglialatela M. Activation and desensitization of TRPV1 channels in sensory neurons by the PPAR $\alpha$ agonist palmitoylethanolamide. Br J Pharmacol 2013;168: 1430-1444.

21. Huang SM, Bisogno T, Trevisani M, et al. An endogenous capsaicin-like substance with high potency at recombinant and native vanilloid VR1 receptors. Proc Natl Acad Sci U S A 2002;99: 8400-8405.

22. Movahed P, Jönsson BA, Birnir B, et al. Endogenous unsaturated $\mathrm{C} 18 \mathrm{~N}$-acylethanolamines are vanilloid receptor (TRPV1) agonists. J Biol Chem 2005;280:38496-38504.

23. Ortar G, Cascio MG, De Petrocellis L, et al. New Narachidonoylserotonin analogues with potential "dual" mechanism of action against pain. J Med Chem 2007;50:6554-6569.

24. Verhoeckx KC, Voortman T, Balvers MG, Hendriks HF, Wortelboer MH, Witkamp RF. Presence, formation and putative biological activities of $\mathrm{N}$-acyl serotonins, a novel class of fatty-acid derived mediators, in the intestinal tract. Biochim Biophys Acta 2011;1811:578-586.

25. Thomas A, Stevenson LA, Wease KN, et al. Evidence that the plant cannabinoid Delta9-tetrahydrocannabivarin is a cannabinoid CB1 and CB2 receptor antagonist. Br J Pharmacol 2005;146:917-926.

26. Bisogno T, Hanus L, De Petrocellis L, et al. Molecular targets for cannabidiol and its synthetic analogues: effect on vanilloid VR1 receptors and on the cellular uptake and enzymatic hydrolysis of anandamide. Br J Pharmacol 2001;134:845-852.

27. de Filippis D, Iuvone T, d'amico A, et al. Effect of cannabidiol on sepsis-induced motility disturbances in mice: involvement of CB receptors and fatty acid amide hydrolase. Neurogastroenterol Motil 2008;20:919-927.

28. Leweke FM, Piomelli D, Pahlisch F, et al. Cannabidiol enhances anandamide signaling and alleviates psychotic symptoms of schizophrenia. Transl Psychiatry 2012;2:e94.

29. McPartland JM, Duncan M, Di Marzo V, Pertwee RG. Are cannabidiol and $\Delta(9)$-tetrahydrocannabivarin negative modulators of the endocannabinoid system? A systematic review. Br J Pharmacol 2015;172:737-753.

30. Pertwee RG. The diverse CB1 and CB2 receptor pharmacology of three plant cannabinoids: delta9-tetrahydrocannabinol, cannabidiol and delta9-tetrahydrocannabivarin. Br J Pharmacol 2008;153:199215.

31. Bolognini D, Costa B, Maione S, et al. The plant cannabinoid Delta9-tetrahydrocannabivarin can decrease signs of inflammation and inflammatory pain in mice. Br J Pharmacol 2010;160:677-687.

32. Priller J, Briley EM, Mansouri J, Devane WA, Mackie K, Felder CC. Mead ethanolamide, a novel eicosanoid, is an agonist for the central (CB1) and peripheral (CB2) cannabinoid receptors. Mol Pharmacol 1995;48:288-292.

33. Brown I, Cascio MG, Wahle KW, et al. Cannabinoid receptordependent and -independent anti-proliferative effects of omega-3 ethanolamides in androgen receptor-positive and -negative prostate cancer cell lines. Carcinogenesis 2010;31:1584-1591.

34. Leggett JD, Aspley S, Beckett SR, D'Antona AM, Kendall DA, Kendall DA. Oleamide is a selective endogenous agonist of rat and human CB1 cannabinoid receptors. Br J Pharmacol 2004;141:253-262.

35. Bisogno T, Maurelli S, Melck D, De Petrocellis L, Di Marzo V. Biosynthesis, uptake, and degradation of anandamide and palmitoylethanolamide in leukocytes. J Biol Chem 1997;272: 3315-3323.

36. Burstein SH, Huang SM, Petros TJ, Rossetti RG, Walker JM, Zurier RB. Regulation of anandamide tissue levels by Narachidonylglycine. Biochem Pharmacol 2002;64:1147-1150.

37. Bradshaw HB, Rimmerman N, Hu SS, et al. The endocannabinoid anandamide is a precursor for the signaling lipid $\mathrm{N}$-arachidonoyl glycine by two distinct pathways. BMC Biochem 2009;10:14.

38. Saghatelian A, McKinney MK, Bandell M, Patapoutian A, Cravatt BF. A FAAH-regulated class of $\mathrm{N}$-acyl taurines that activates TRP ion channels. Biochemistry 2006;45:9007-9015.

39. Di Marzo V, Melck D, Orlando P, et al. Palmitoylethanolamide inhibits the expression of fatty acid amide hydrolase and enhances the anti-proliferative effect of anandamide in human breast cancer cells. Biochem J 2001;358:249-255.

40. Ben-Shabat S, Fride E, Sheskin T, et al. An entourage effect: inactive endogenous fatty acid glycerol esters enhance 2-arachidonoylglycerol cannabinoid activity. Eur J Pharmacol 1998;353:23-31.

41. Alexander S. Common receptors for endocannabinoid-like mediators and plant cannabinoids. In: Di Marzo V, Wang J (eds) The endocannabinoidome. Academic Press, London, 2015, pp. 153167.

42. Ryberg E, Larsson N, Sjögren S, et al. The orphan receptor GPR55 is a novel cannabinoid receptor. Br J Pharmacol 2007;152:10921101.

43. Martínez-Pinilla E, Reyes-Resina I, Oñatibia-Astibia A, et al. CB1 and GPR55 receptors are co-expressed and form heteromers in rat and monkey striatum. Exp Neurol 2014;261:44-52.

44. Sharir H, Console-Bram L, Mundy C, Popoff SN, Kapur A, Abood ME. The endocannabinoids anandamide and virodhamine modulate the activity of the candidate cannabinoid receptor GPR55. J Neuroimmune Pharmacol 2012;7:856-865.

45. Kapur A, Zhao P, Sharir H, et al. Atypical responsiveness of the orphan receptor GPR55 to cannabinoid ligands. J Biol Chem 2009;284:29817-29827.

46. Zhao P, Abood ME. GPR55 and GPR35 and their relationship to cannabinoid and lysophospholipid receptors. Life Sci 2013;92: 453-457.

47. Kohno M, Hasegawa $\mathrm{H}$, Inoue A, et al. Identification of $\mathrm{N}$ arachidonylglycine as the endogenous ligand for orphan Gprotein-coupled receptor GPR18. Biochem Biophys Res Commun 2006;347:827-832.

48. Console-Bram L, Brailoiu E, Brailoiu GC, Sharir H, Abood ME. Activation of GPR18 by cannabinoid compounds: a tale of biased agonism. Br J Pharmacol 2014;171:3908-3917.

49. Cazade M, Nuss CE, Bidaud I, et al. Cross-modulation and molecular interaction at the Cav3.3 protein between the endogenous lipids and the T-type calcium channel antagonist TTA-A2. Mol Pharmacol 2014;85:218-225.

50. Ross HR, Napier I, Connor M. Inhibition of recombinant human Ttype calcium channels by Delta9-tetrahydrocannabinol and cannabidiol. J Biol Chem 2008;283:16124-16134.

51. Lo Verme J, Fu J, Astarita G, et al. The nuclear receptor peroxisome proliferator-activated receptor-alpha mediates the anti-inflammatory actions of palmitoylethanolamide. Mol Pharmacol 2005;67:15-19. 
52. Sun Y, Alexander SP, Garle MJ, et al. Cannabinoid activation of PPAR alpha; a novel neuroprotective mechanism. Br J Pharmacol 2007; 152:734-743.

53. Scuderi C, Steardo L, Esposito G. Cannabidiol promotes amyloid precursor protein ubiquitination and reduction of beta amyloid expression in SHSY5YAPP+ cells through PPAR $\gamma$ involvement. Phytother Res 2014;28:1007-1113.

54. O'Sullivan SE. Cannabinoids go nuclear: evidence for activation of peroxisome proliferator-activated receptors. Br J Pharmacol 2007; 152:576-582.

55. McDougle DR, Kambalyal A, Meling DD, Das A. Endocannabinoids anandamide and 2-arachidonoylglycerol are substrates for human CYP2J2 epoxygenase. J Pharmacol Exp Ther 2014;351:616-627.

56. Bornheim LM, Everhart ET, Li J, Correia MA. Characterization of cannabidiol-mediated cytochrome P450 inactivation. Biochem Pharmacol 1993;45:1323-1331.

57. Takeda S, Misawa K, Yamamoto I, Watanabe K. Cannabidiolic acid as a selective cyclooxygenase-2 inhibitory component in cannabis. Drug Metab Dispos 2008;36: 1917-1921.

58. Di Marzo V. Targeting the endocannabinoid system: to enhance or reduce. Nat Rev Drug Discov 2008;7:438-455. 